\section{A Method to Screen Pome Fruit for Resistance to Skin-chewing Insects and to Analyze Feeding Trends}

\author{
Christian Chervin ${ }^{1}$ \\ CSIRO Plant Industry, Horticulture Unit, Private Bag 15, South East Mail \\ Centre, VIC 3176, Australia
}

Peter Franz

Agriculture Victoria Biometrics, Private Bag 15, South East Mail Centre, VIC 3176, Australia

\author{
Sarita Kulkarni, Steve Whitmore, and Graeme McGregor \\ Institutefor Horticultural Development, Private Bag 15, South East Mail Centre, \\ VIC 3176, Australia
}

\begin{abstract}
Additional index words. apple, pear, Rosaceae, Malus $\times$ domestica, Pyrus communis, Pyrus pyrifolia, Pyrus $\times$ bretschneideri, lightbrown apple moth, Epiphyas postvittana, plant-insect, insect-plant interactions
\end{abstract}

\begin{abstract}
Insect feeding traces on fruit are a major concern to orchardists. Breeding fruit for insect resistance is becoming more important as available pesticides are limited by more stringent regulations, problems of insect resistance, and residue limits. We present a method to analyze fruit skin damage via treatment of video images. This aspect has not been well studied to date, but would allow a more rapid assessment of fruit resistance to insects in breeding programs. The method uses equipment available on the world video and computer markets. Over 24 hours, larvae of lightbrown apple moth [Epiphyas postvittana Walker (Lepidoptera: Tortricidae)] were permitted to chew restricted areas of skin on the pear cultivars Sensation Red Bartlett, Packham's Triumph, Doyenne du Comice, Beurre d'Anjou, and Corella (Pyrus communis L.); Twentieth Century (Pyrus pyrifolia Burm. Nak.); Ya Li (Pyrus $\times$ bretschneideri Rehd.); and $F_{1}$ hybrids of 'Packham's Triumph' $x$ 'Twentieth Century'. Optimum experimental conditions and statistical analyses are described and sensitivity of the various cultivars is discussed. The method allowed us to identify some highly resistant and sensitive pear hybrids. The ability to rapidly screen $F_{1}$ hybrids for insect resistance may encourage breeders to incorporate such a factor in breeding programs, and should hasten the release of resistant cultivars. The application of this technique in the orchard is discussed. The method also allows the analysis of various aspects of larval feeding, such as number and size of wounds, which may be responses to various fruit skin defense systems.
\end{abstract}

Increasing restrictions on the use of chemicals in agriculture are leading to the development of integrated pest management. Therefore, interest in breeding and selection for natural or engineered plants that are resistant to pest damage is increasing (Smith and Quisenberry, 1994). Breeding for natural resistance is rarely incorporated early, if at all,

Received for publication 30 July 1998. Accepted for publication 1 Oct. 1999. We acknowledge the Baker Trust, the Australian Apple and Pear Growers Association, and the Horticultural Research and Development Corp. for grants (AP520 and AP632) in support of this study. We thank Sue Richards and Leigh Issell (Agriculture Victoria) for their help in collecting fruit and data at Tatura, and Jean Bentley, DeAnn Glenn, Philip Moyle, and Stephen Walsh (Agriculture Victoria) for help in setting the video. The cost of publishing this paper was defrayed in part by the payment of page charges. Under postal regulations, this paper therefore must be hereby marked advertisement solely to indicate this fact. ${ }^{1}$ Current address: Ecole Nationale Supérieure Agronomique de Toulouse, BP 107, 31326 Castanet, France. E-mail address: chervin@ensat.fr in selection programs, as it is often laborintensive (Dent, 1991). Thus, progress in this field requires development of practical methods. Superficial damage caused to fruit by chewing insects is a cause of concern in most areas of production (Grauslund et al., 1993; Hull et al., 1983; McLellan, 1979). As underlined in these studies, the most common chewing insects are lepidopterous larvae, such as the Australian native pest, lightbrown apple moth. The most serious damage (Fig. 1a) occurs in the orchard mainly on immature fruit, as tested in this study. The wounds enlarge as fruit grow, and may cause abnormal fruit shape.

We present a method to assess the feeding ability of such larvae on the skin of pome fruit. The resistance of the plant to the insect is likely to be the result of multiple genes, known as horizontal resistance (Dent, 1991; Wiseman, 1994). These authors considered it to be a more permanent form of resistance than vertical resistance, which is due to a single gene. Cases in which insects overcome vertical resistance are well known (Stoner, 1996). The factors influ- encing host plant resistance to insects are complex and have been the subject of many articles and reviews (Eigenbrode and Espelie, 1995; Hochuli, 1996; Schoonhoven, 1996).

The percentage of area damaged on fruit skin is hard to quantify. Some techniques have been developed to assess insect feeding ability on leaves. These include measuring the area chewed using the amount of light transmitted through a leaf (Pedigo et al., 1970), or video devices and software designed for this particular purpose (Hargrove and Crossley, 1988; Lindow and Webb, 1983). These can be applied to fruit, but they are not distributed on the computer market. We describe a method that uses equipment available worldwide, and we present the results of studies to develop this method for bulky plant organs like fruit. Possible analyses of insect feeding trends and fruit breeding are discussed.

\section{Materials and Methods}

Commercial cultivars. Immature pear fruit were harvested from the orchard of the research station of Agriculture Victoria at Tatura, Australia, in 1997. The commercial cultivars Sensation Red Bartlett, Packham's Triumph, Twentieth Century (syn. Nijisseiki), Ya Li, Doyenne du Comice, Beurre d'Anjou, and Corella were picked on the same day at 100,107, 107, 121, 100, 111, and $114 \mathrm{~d}$ after full bloom (DAFB), respectively. For the first four cultivars, 10 fruit were picked from each of five different trees. For the last three, 10 fruit were picked from each of three trees. 'Corella' and 'Beurre d'Anjou' pears showed $\approx 50 \%$ of red and $50 \%$ of green skin on opposite sides, for which separate assessments were performed.

Hybrid seedlings. The tests were also performed on fruit from $\mathrm{F}_{1}$ hybrid seedlings of 'Packham's Triumph' $x$ 'Twentieth Century' from the same orchard in 1998. Ten immature fruit were picked from each of 67 different seedling trees 100 to 110 DAFB.

Insects. Lightbrown apple moth was chosen as the insect model, as it feeds on a wide range of plants, including fruit crops (Danthanarayana, 1975), and thus seems capable of circumventing various plant defenses. The insects were reared according to Shorey and Hale (1965). In the rearing medium, formaldehyde was replaced with propionic acid $(0.14 \%$ final concentration) and orthophosphoric acid $(0.014 \%)$ for safety purposes. The temperature of the rearing chamber was $19^{\circ} \mathrm{C}$ with a 12 -h photoperiod.

Fifth instar larvae (head capsule size $=0.98$ $\pm 0.14 \mathrm{~mm}, \mathrm{n}=30$, randomly chosen among all test batches) were placed in 5-mL polycarbonate vials, which were attached to the surface of the fruit by partially waxing their edges (Fig. 1b). One larva was used per vial and one vial per fruit. For 'Corella' and 'Beurre d'Anjou' two larvae were applied per fruit (one on the green side, one on the red). In the second year, for the experiment with hybrid fruit, the wax was replaced by adhesive gum placed around the vial. This was quicker and as efficient as the waxing process. Preliminary experiments showed that $24 \mathrm{~h}$ of incubation in the rearing chamber was necessary to achieve sufficient feeding dam- 


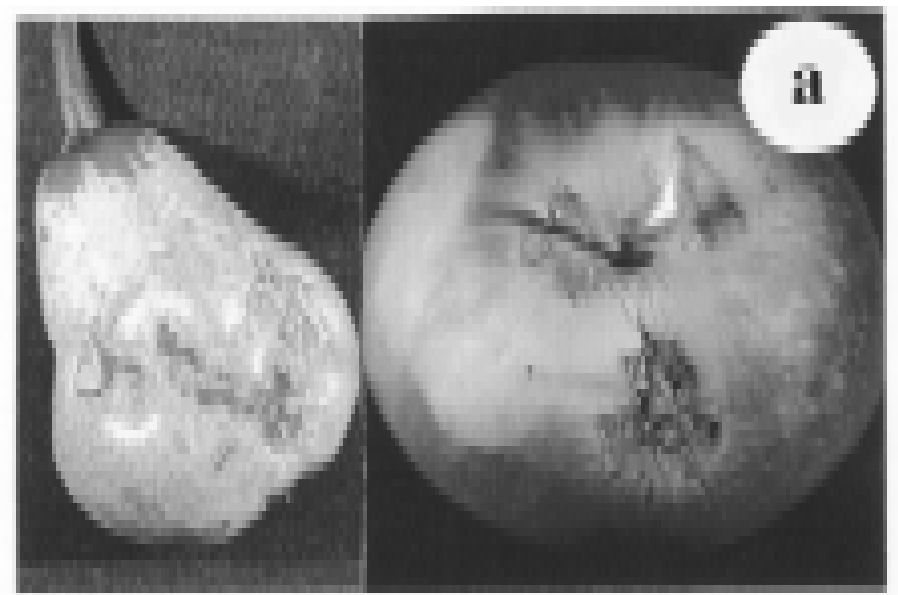

of the samples, the larvae fed only on the skin. Some larvae burrowed into the fruit flesh slightly $(2-5 \mathrm{~mm})$. However, this feeding was not measured, because only the area was detectable on the video image.

Images of fruit were taken with a video camera (model TK C1381EG; JVC, Tokyo) equipped with a zoom lens (Cosmicar ES 12.5-75 mm, Englewood, Colo.). The camera was connected to a video monitor, which was linked to a computer equipped with the frame grabber Targa+ (TrueVision, Santa Clara, Calif.). Some frame grabbers do not require the use of the extra video monitor. The images were saved as 8-bit grey scale image files, using the SigmaScanPro image measurement software (SPSS, Chicago). This software is one of many that allows the measurement of an area by flooding a zone of defined contrast. All fruit were placed $1 \mathrm{~m}$ from the camera to allow comparison. For area recognition, the grey intensity threshold delimiting the edges of the wound can be read on the computer screen by moving the cursor across the edges. The threshold can then be set so that the area marked by the software exactly matches the wounded area. The measurements were then achieved by clicking once on wound areas, and the area values were automatically reported in an attached table. The total area on each fruit available to one larva was estimated by inking the top edge of the vial and pressing it to the fruit skin. The area determined by the video-computer system was initially determined in square pixels. To express the results in metric units, calibration was obtained by comparing the mean of 10 total areas $=24,505 \pm 433$ pixel $^{2}$ (mean $\pm \mathrm{SE}$ ) to the known area of the vial opening $\left(154 \mathrm{~mm}^{2}\right)$.

Data analysis. Feeding ability was analyzed in two steps. The total area fed upon and the number of wounds per fruit were recorded only for fruit on which feeding was observed. The area/wound was then calculated. The experimental unit was the individual fruit. In the cultivar comparison analyses for 'Beurre d'Anjou' and 'Corella', data obtained on green and red sides were analyzed separately to compare the effect of color on feeding. The results were analyzed using analysis of variance and Kolmogorov-Smirnov normality tests (SigmaStat, version 2, SPSS). Multiple comparison analyses were made using Tukey's test. Fruit with missing larvae or larvae that pupated were not considered in the analyses.

Fig. 1. (a) Damage caused by lightbrown apple moth larvae on 'Packham's Triumph' pear and 'Pink Lady' apple; (b) a lightbrown apple moth larva enclosed in a tube partly affixed with wax to a 'Twentieth Century' pear, prior to the feeding test period; wax can be replaced by adhesive gum; (c) the area chewed was highlighted by dipping the fruit in talc powder, after the test period and before image analysis; talc was not necessary in all cases (see Materials and Methods).

age. After this period, the larvae were removed and the fruit was stored for a maximum of 1 month at $0{ }^{\circ} \mathrm{C}$ in plastic bags to prevent desiccation until further analysis.

Video imaging. On the day of video imaging, fruit were removed from cold storage and left at ambient temperature for $\approx 10 \mathrm{~min}$. Excess water from condensation was wiped with a tissue. The chewed areas that were still wet were then coated with talc powder (Fig. 1c) 30 min prior to video imaging and allowed to dry. This process increased the contrast on the black and white image. In the second year, the talc was not employed, as the chewed area on most hybrids rapidly darkened and presented sufficient contrast to be recognized by the software. The few damaged areas not dark enough were blackened with a marker. In $95 \%$

\section{Results and Discussion}

Practicality of the method. Assessing the insect resistance of the fruit of 75 trees can be achieved in a week (on the basis of 10 fruit/tree and $30 \mathrm{~h} /$ week). This can be divided into three steps: 1) selection of larvae, 2) infestation, and 3) image capture and analysis. Selecting the larvae and placing in individual vials can be achieved at a rate of 50 larvae/h. The vials should be closed temporarily to prevent the escape of larvae. The vials can be set on fruit at a rate of $100 \mathrm{fruit} / \mathrm{h}$. The images can be scanned and the chewed area computed at a rate of 100 images $/ \mathrm{h}$. These estimates were determined 
during the second year trial. The major limiting factor is the size of the insect colony, which needs to be adjusted to the experimental design to be able to find the required number of larvae of the required instar at one time.

The method was developed with harvested fruit, but could easily be adapted for fruit on the tree. Once the larvae are selected, they can be brought to the orchard where infestation can probably be achieved at the rate cited above. If field applications are considered, vials with aeration holes should be used to avoid plant volatile accumulation and water condensation. The vials could be placed on the shady side of the fruit or tree to avoid overheating. Image capture can at present be achieved with small digital cameras. The risk of introducing large numbers of pests in the orchard is limited, as there were only four missing larvae out of 670 larvae set onto fruit within the 24-h experiment.

The nature of the vials (e.g., polycarbonate) may induce some volatiles to be released in the headspace, which may influence feeding behavior of the insects. This fact restricts the use of this method to comparisons between treatments or with a control assayed in an identical manner.

Commercial cultivars. Cultivars differed in the total amount of skin chewed (Fig. 2a), Larvae fed up to 3.4 times more on 'Sensation' than on 'Ya Li' pears. These two cultivars have an obvious visual difference in that the skin of 'Sensation' was mostly red, whereas that of 'Ya Li' was all green. However, the difference in feeding is unlikely to be due to differing pigments, because feeding was not significantly different between the green and red sides of 'Beurre d'Anjou' and 'Corella'.

The causes of differences in feeding ability are numerous and have been studied on many crops in relation to various phytophagous insect larvae. Among these causes, studies have highlighted the effects of compounds that either render the plant less digestible, e.g., cellulose or lignin (Hochuli, 1996), or more attractive, e.g., surface nutrients (Städler, 1986). All of these compounds could influence the amounts of skin chewed. Differences in feeding behavior cannot be caused only by a difference in skin color, the red color in pome fruit skin being due to a complex blend of anthocyanins, flavonols, and others compounds (Lancaster, 1992). The difference in feeding on 'Sensation' and 'Ya Li' may also be related to the time difference between bloom and harvest, that is, to differences in fruit maturity, but this was not tested in this experiment. If fruit maturity is important, integrated pest management practices may be influenced (i.e., fewer insecticide treatments may be needed as fruit approach maturity). In any case, DAFB and other measures of maturity should be critical parameters in further development of this method.

In addition to the total area chewed, the image analysis system allowed us to count the number of wounds made by each larva. The mean surface area of each wound (Fig. 2b) indicates that the relatively large area chewed on 'Comice' fruit (Fig. 2a) was the result of
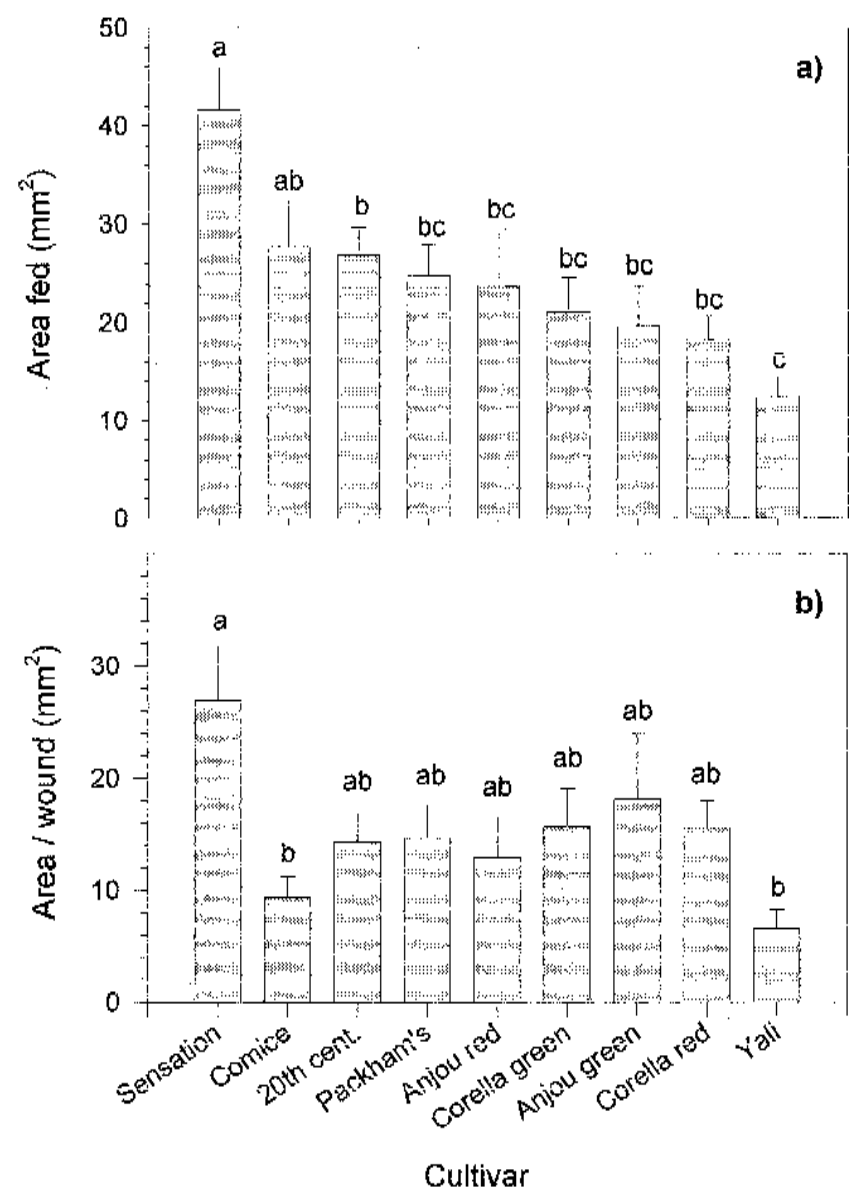

Fig. 2. (a) Mean area consumed by one lightbrown apple moth larva in $24 \mathrm{~h}$ on one fruit of each of seven commercial pear cultivars; (b) mean area per wound. Mean separation by Tukey's test $(P \leq 0.05)$. Means are based upon 30-50 fruit per cultivar. The adjective "red" or "green" are for data collected on red or green sides of 'Corella' or 'Beurre d'Anjou' fruit.

higher numbers of smaller wounds than on 'Sensation'. This may reflect some properties of 'Comice' skin that prevented continuous feeding, such as compounds that cause a rejection response, as observed in other lepidopterous larvae (Glendinning, 1996). Some chemical components of the cuticle or skin of 'Ya Li' pears may have reduced the larval feeding time, relative to that on 'Comice', as total area chewed was smaller (Fig. 2a) despite similar area/wound (Fig. 2b). Time studies over the feeding period could determine whether large wounds result from continuous feeding or from small wounds joined together by more frequent feeding episodes.

The above results did not take into account the cases in which larvae did not feed at all. The absence of feeding ranged from $42 \%$ for the red side of 'Corella' to $10 \%$ for 'Twentieth Century'. The mean among all cultivars was $22 \%$ nonwounded fruit. The only significant difference $(P \leq 0.05)$ was between the red side of 'Corella' and 'Twentieth Century'. Measuring the absence of feeding may be worthwhile in breeding programs, but the method described here may not be suitable. The use of the vial to restrict the larva to the fruit prevents it from choosing between the fruit and other parts of the plant, a choice that is important in larval establishment (Suckling and Ioriatti, 1996).
Hybrid seedlings. The frequency distribution of the feeding area on fruit of 67 hybrid lines was graphed (Fig. 3). The normality test failed, with a K-S distance $=0.228$ and $P=$ 0.002 . Figure 3 illustrates the wide variation in insect resistance that can be obtained in the first generation. There were three noticeable groups of hybrids. For one group (four hybrids) damage was $\leq 20 \mathrm{~mm}^{2}$, revealing some natural resistance in the fruit. For a second group (60 hybrids) damage averaged $40-45 \mathrm{~mm}^{2}$, the median sensitivity of most hybrids, and for a third group (three hybrids) it exceeded $100 \mathrm{~mm}^{2}$, revealing high sensitivity to larval feeding. The variations in feeding ability by the larvae seemed related neither to the size of the fruit, as there were both large or small fruit, with diameters ranging from 3 to $5 \mathrm{~cm}$ among both resistant and sensitive hybrids, nor to the color of the skin, as all fruit were green except for one resistant hybrid. The skin of its fruit was totally russeted, and probably provided some mechanical and/ or chemical defense (Faust and Shear, 1972).

The above results take into account only fruit on which larvae fed. Nonwounded fruit varied from $0 \%$ to $70 \%$ among all hybrids, with a mean of $38 \%$, but the correlation between area fed and absence of feeding was weak, with a logical tendency for small area being related to high absence of feeding (data not shown). 


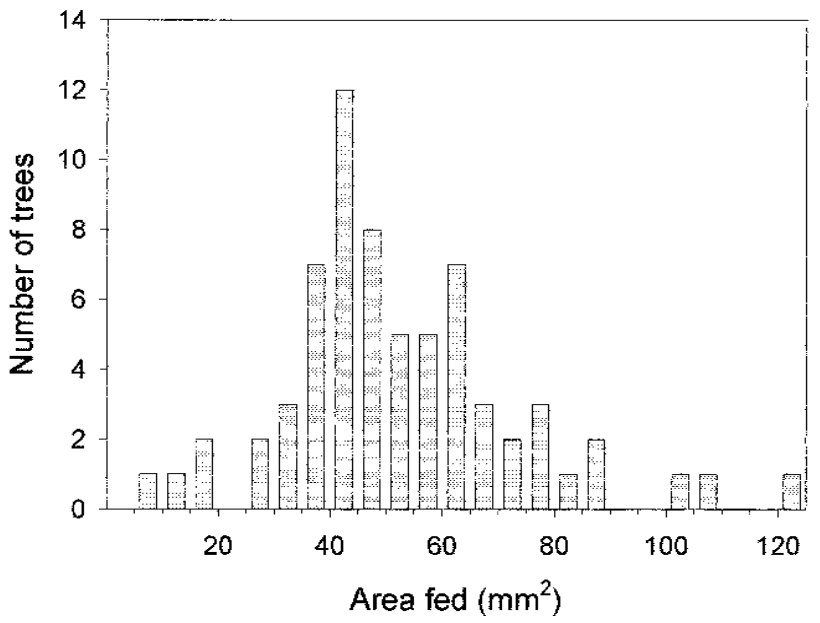

Fig. 3. Frequency distribution of the mean area fed on fruit surface among 67 'Packham's Triumph' $x$ 'Twentieth Century' hybrid $\left(\mathrm{F}_{1}\right)$ trees, based on $5-\mathrm{mm}^{2}$ classes. Fruit with no damage were excluded.

\section{Conclusion}

The method presented here offers possibilities to quantify the amount of insect damage to fruit skin, an aspect that has not been well studied. This method uses standard, readily available video equipment and software. It would allow the screening of hybrids at an early stage of breeding (with an average rate of 75 per week).

The fruit skin of the Pyrus species apparently possesses some mechanism of resistance to larval feeding, as could be expected, given the broad range of skin textures and colors in this genus (Hummer, 1989). The resistance developed by the skin can probably be ascribed to a complex range of plant defenses (Schoonhoven, 1996). The different feeding trends described in this paper suggest that pears possess various mechanical and/or chemical defenses leading to smaller wounds by insect larvae. Also, breeding for deterrent effects may seem more advantageous, as they may result in smaller amounts of wounded fruit. However, all fruit properties that limit insect feeding ability may result in lower population densities, which would improve crop quality over a whole season.

In natural situations, the adaptation of insects to plant defenses through feeding exposure (Lindroth and Weisbrod, 1991; Papaj and Prokopy, 1989) may result in increased larval feeding. This could be checked by varying the rearing medium (i.e., leaves or fruitlets) before starting the feeding test. Other factors, such as attraction to volatiles and nesting possibilities, may also influence damage to fruit skin (Suckling and Ioriatti, 1996). However, the larval feeding ability per se remains a critical factor. Under natural conditions, when the fruit skin is not appreciated by the larvae, they tend to feed on leaves only. In our experiment, because of the absence of choice, the larvae may have fed on fruit, whereas in the orchard they would not have. Thus, we may slightly underestimate the natural resistance of a fruit by this method.

\section{Literature Cited}

Danthanarayana, W. 1975. The bionomics, distribution and host range of the light brown apple moth, Epiphyas postvittana (Walk.) (Tortricidae). Austral. J. Zool. 23:419-437.

Dent, D.R. 1991. Host plant resistance, p. 213292. In: Insect pest management. CAB Intl., Oxon, U.K.

Eigenbrode, S.D. and K.E. Espelie. 1995. Effects of plant epicuticular lipids on insect herbivores. Annu. Rev. Entomol. 40:171-194.

Faust, M. and C.B. Shear. 1972. Russeting of apples, an interpretive review. HortScience 7:233-235.

Glendinning, J.I. 1996. Is chemosensory input essential for the rapid rejection of toxic foods? J. Expt. Biol. 199:1523-1534.

Grauslund, J., H. Lindhard, J.V. Christensen, A.M.E. Schenk, A.D. Webster, and S.J.
Wertheim. 1993. An experiment to compare integrated and conventional spray programmes in eight apple cultivars. Acta Hort. 347:57-63.

Hargrove, W.W. and D.A. Crossley, Jr. 1988. Video digitizer for the rapid measurement of leaf area lost to herbivorous insects. Ann. Entomol. Soc. Amer. 81:593-598.

Hochuli, D.F. 1996. The ecology of plant/insect interactions: Implications of digestive strategy for feeding by phytophagous insects. Oikos 75:133-141.

Hull, L.A., K.D. Hickey, and W.W. Kanour. 1983. Pesticide usage patterns and associated pest damage in commercial apple orchards of Pennsylvania. J. Econ. Entomol. 76:577-583.

Hummer, K. 1989. Fruit germplasm preservation. HortScience 24:190.

Lancaster, J.E. 1992. Regulation of skin colour in apples. Crit. Rev. Plant Sci. 10:487-502.

Lindow, S.E. and R.R. Webb. 1983. Quantification of foliar plant disease symptoms by microcomputer-digitized video image analysis. Phytopathology 73:520-524.

Lindroth, R.L. and A.V. Weisbrod. 1991. Genetic variation in response of the gypsy moth to aspen phenolic glycosides. Biochem. System. Ecol. 19:97-103.

McLellan, C.R. 1979. Pest damage and insect fauna of Nova Scotia apple orchards: 1953-1977. Can. Entomol. 111:985-1004.

Papaj, D.R. and R.J. Prokopy. 1989. Ecological and evolutionary aspects of learning in phytophagous insects. Annu. Rev. Entomol. 34:315-350.

Pedigo, L.P., J.D. Stone, and R.B. Clemen. 1970 Photometric device for measuring foliage loss caused by insects. Ann. Entomol. Soc. Amer. 63:815-818.

Schoonhoven, L.M. 1996. After the VershaffeltDethier era: The insect-plant field comes of age. Entomol. Expt. Appl. 80:1-5.

Shorey, H.H. and R.L. Hale. 1965. Mass-rearing of the larvae of nine noctuid species on a simple artificial medium. J. Econ. Entomol. 58:522524.

Smith, C.M. and S.S. Quisenberry. 1994. The value and use of plant resistance to insects in integrated crop management. J. Agr. Entomol. 11:189-190.

Städler, E. 1986. Oviposition and feeding stimuli in leaf surfaces waxes, p. 105-121. In: B.E. Juniper and T.R.E. Southwood (eds.). Insects and plant surface. Edward Arnold, London.

Stoner, K.A. 1996. Plant resistance to insects: A resource available for sustainable agriculture. Biol. Agr. Hort. 13:7-38.

Suckling, D.M. and C. Ioriatti. 1996. Behavioral responses of leafroller larvae to apple leaves and fruit. Entomol. Expt. Appl. 81:97-103.

Wiseman, B.R. 1994. Plant resistance to insects in integrated pest management. Plant Dis. 78:927932 . 